\title{
PRODUTIVIDADE DO FEIJOEIRO DE INVERNO SOB DIFERENTES PALHADAS DE ESPÉCIES FORRAGEIRAS E ÉPOCAS DE APLICAÇÃO DE NITROGÊNIO
}

\author{
Gabriela Tedeschi ${ }^{1}$, Marcelo Andreotti ${ }^{2}$, Leonardo Tedeschi ${ }^{3}$, Mariana Fogale de Andrade ${ }^{3}$, \\ Poliana Aparecida Leonel Rosa ${ }^{4}$, Nídia Raquel Costa ${ }^{5}$
}

\footnotetext{
${ }^{1}$ Graduanda em Agronomia, Universidade Estadual Paulista (UNESP), Faculdade de Engenharia, Campus de Ilha Solteira (SP). Email: gabi_tedeschi@ hotmail.com

${ }^{2}$ Professor Adjunto do Departamento de Fitotecnia, Engenharia Rural e Solos, Universidade Estadual Paulista (UNESP), Faculdade de Engenharia, Campus de Ilha Solteira (SP).

${ }^{3}$ Graduados (as) em Zootecnia, Universidade Estadual Paulista (UNESP), Faculdade de Engenharia, Campus de Ilha Solteira (SP).

${ }^{4}$ Doutoranda em Sistemas de Produção, Universidade Estadual Paulista (UNESP), Faculdade de Engenharia, Campus de Ilha Solteira (SP).

${ }^{5}$ Pós-Doutoranda, Universidade Estadual Paulista Júlio de Mesquita Filho (UNESP), Faculdade de Ciências Agronômicas - Departamento de Produção e Melhoramento Vegetal, Campus de Botucatu (SP).
}

RESUMO: O uso intensivo de gramíneas em áreas de implantação de sistemas consorciados de produção agrícola sob sistema plantio direto (SPD), pode promover uma imobilização temporária do nitrogênio $(\mathrm{N})$ no solo. O presente trabalho objetivou avaliar o efeito da adubação nitrogenada $\left(70 \mathrm{~kg} \mathrm{~N} \mathrm{ha}^{-1}\right)$, em dose única na semeadura ou em cobertura sobre a nutrição, os componentes da produção e a produtividade de grãos do feijoeiro de inverno em sucessão ao consórcio das culturas do milho e capim-xaraés, sob diferentes palhadas de plantas de cobertura em condições irrigadas no Cerrado. O experimento foi instalado em delineamento de blocos casualizados, com quatro repetições, em esquema fatorial $4 \times 2 \times 2$. Os tratamentos foram constituídos por 4 espécies de plantas forrageiras (aveia preta cv. IAPAR 61, sorgo forrageiro cv. Volumax, milheto e capim-tanzânia) semeadas em 2 épocas (junho e julho), visando a formação de palhada para o cultivo das culturas do milho e capim-xaraés em consórcio, além de 2 épocas de adubação nitrogenada na cultura do feijão de inverno em sucessão. As espécies antecessoras ao cultivo do milho em consórcio com o capim-xaraés, não alteraram a nutrição, os componentes da produção e produtividade de grãos do feijoeiro de inverno em sucessão. Em áreas de solo argiloso, com características de implantação do SPD (primeiros 3 anos), a adubação nitrogenada com toda a dose em semeadura aumentou a produtividade de grãos de feijão de inverno em condições de Cerrado de baixa altitude.

Palavras-chave: Phaseolus vulgaris. Nitrato de amônio. Sistema plantio direto. Consórcio entre culturas.

\section{WINTER BEAN YIELD UNDER DIFFERENT FORAGES SPECIES STRAWS AND NITROGEN FERTILIZATION TIMES}

Cultura Agronômica, Ilha Solteira, v.26, n.3, p.285-296, 2017 


\begin{abstract}
The intensive use of forage grasses in intercropping systems in deployment areas of agricultural production under no-tillage system (NTS), can promote a temporary immobilization of nitrogen $(\mathrm{N})$ in the soil. This study aimed to evaluate the effect of nitrogen fertilization $\left(70 \mathrm{~kg} \mathrm{~N} \mathrm{ha}^{-1}\right)$ as a single dose at sowing or coverage in the nutrition, the components of the production and productivity of winter bean grains in succession to the corn and palisadegrass in intercropping system under different straws cover crops in irrigated conditions in the Cerrado. The experiment was conducted in a randomized block design with four replications, in a factorial $4 \times 2 \times 2$. The treatments were 4 species of forage plants (oat cv. IAPAR 61, forage sorghum cv. Volumax, millet and guineagrass) seeded in 2 times (June and July), to the straw training for the cultivation of crops corn and xaraés grass in consortium, in addition to 2 nitrogen fertilizer times in winter bean crop in succession. The predecessor species to corn intercropped with palisadegrass, did not alter the nutrition, the components of production and productivity of winter bean grains in succession. In areas with clay soil, with the NTS implementation characteristics (first 3 years), nitrogen fertilization with full dose at sowing increased the productivity of winter beans in the Brazilian Cerrado lowlands.
\end{abstract}

Key words: Phaseolus vulgaris. Ammonium nitrate. No-tillage system. Intercropping crops.

\title{
INTRODUÇÃO
}

O feijoeiro comum (Phaseolus vulgaris L.) é considerado uma planta muito exigente em nutrientes, principalmente em nitrogênio (N) (FAGERIA; BALIGAR, 2005, COSTA et $a l .$, 2016). Na implantação de sistemas consorciados de produção agrícola e do sistema de Integração Lavoura-Pecuária (ILP) sob plantio direto (SPD), a disponibilidade de nutrientes, principalmente do $\mathrm{N}$, pode influenciar a adequada nutrição da cultura, que entra neste sistema produtivo a fim de quebrar o ciclo de espécies gramíneas na área (COSTA et al., 2016).

A adubação nitrogenada é recomendada para atender às exigências da cultura, principalmente no SPD após gramíneas, a fim de garantir elevadas produtividades de grãos (MEIRA et al., 2005; SILVEIRA et al., 2005; COSTA et al., 2016). Em sistemas produtivos agrícolas, a fertilização, a ciclagem de nutrientes e o incremento do teor de matéria orgânica do solo são importantes, a fim de proporcionar a nutrição adequada das plantas de feijão.

Por ser um nutriente que se perde facilmente no sistema solo-planta, o manejo adequado do $\mathrm{N}$ é considerado um dos mais difíceis. Dessa forma, técnicas de manejo que possibilitem a otimização da absorção de N pelo feijoeiro são muito importantes. Assim, o correto manejo da adubação nitrogenada no feijoeiro em sistemas produtivos mais tecnificados, que utilizam irrigação, consórcio de culturas sob SPD, e mais recentemente a ILP, torna-se de extrema relevância a fim de proporcionar maior eficiência produtiva e maior sustentabilidade ambiental.

Cultura Agronômica, Ilha Solteira, v.26, n.3, p.285-296, 2017 
Sendo assim, o presente trabalho objetivou avaliar o efeito da adubação nitrogenada (70 kg N ha ${ }^{-1}$ - fonte nitrato de amônio), em dose única na semeadura ou em cobertura sobre a nutrição, os componentes da produção e a produtividade de grãos do feijoeiro de inverno em sucessão ao consórcio das culturas do milho e capim-xaraés, sob diferentes palhadas de plantas de cobertura em condições irrigadas na região de Cerrado de baixa altitude.

\section{MATERIAL E MÉTODOS}

O experimento foi conduzido no ano agrícola de 2013/2014, na Fazenda de Ensino, Pesquisa e Extensão, pertencente à Faculdade de Engenharia, Campus de Ilha Solteira (FE/Unesp), área de Produção Vegetal, localizada no município de Selvíria, Estado de Mato Grosso do Sul (20²0’05”S e 51²4’26”W, altitude de $335 \mathrm{~m})$.

O tipo climático é Aw, segundo classificação de Köppen, caracterizado como tropical úmido com estação chuvosa no verão e seca no inverno. Na Figura 1, estão apresentados os dados de precipitação pluvial, temperaturas mínima, média e máxima durante o período de condução do experimento.

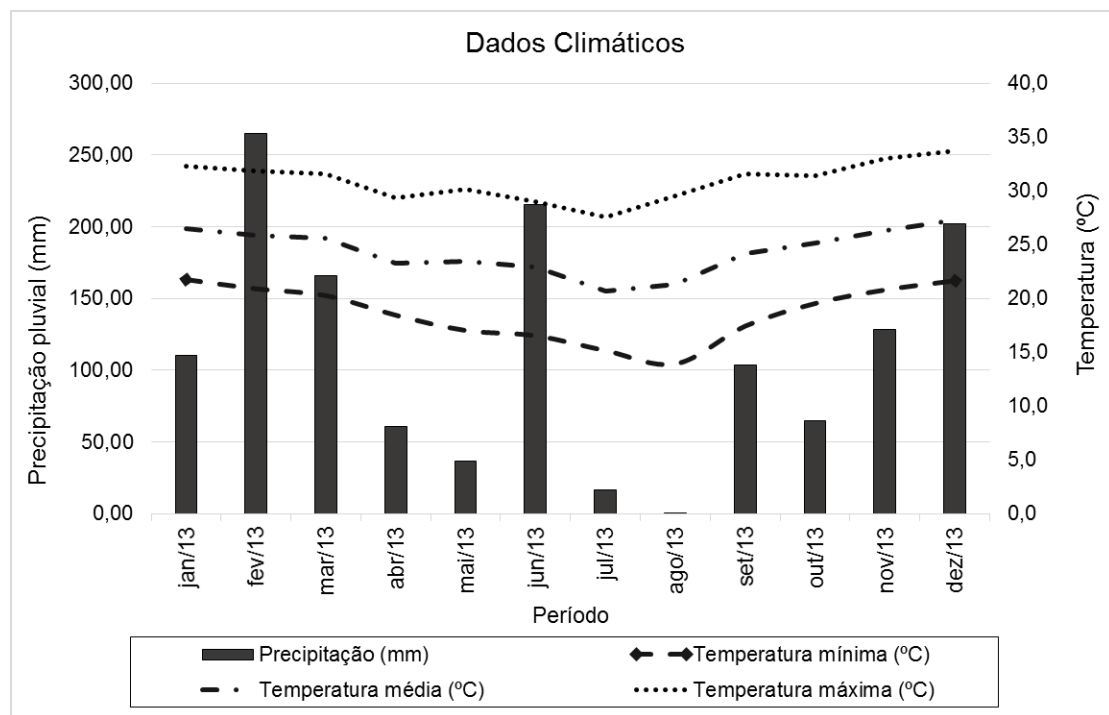

Figura 1. Dados de precipitação pluvial, temperaturas mínima, média e máxima, obtidos na estação meteorológica situada na Fazenda de Ensino, Pesquisa e Extensão da FE/UNESP, no município de Selvíria, Mato Grosso do Sul. Período de Janeiro a Dezembro/2013.

O solo no qual foi estabelecida a pesquisa é classificado como um LATOSSOLO VERMELHO Distrófico textura argilosa (EMBRAPA, 2006) e estava sendo cultivado com culturas anuais em implantação do sistema plantio direto (SPD) há dois anos (anos agrícolas 2011/2012 e 2012/2013). Para tanto, foram utilizadas quatro espécies forrageiras, sendo uma forrageira de inverno e três forrageiras tropicais (aveia preta, milheto, sorgo forrageiro e capim-tanzânia). Posteriormente, porém ainda na safra 2012/2013, realizou-se o cultivo da cultura do milho em consórcio com o capim-xaraés sobre a palhada das forrageiras. Após a 
colheita da cultura do milho e dessecação do capim-xaraés (23/03/2013), foi realizada a semeadura do feijoeiro de inverno em sucessão (13/06/2013). A área foi irrigada por aspersão (pivô central), quando necessário, em função de déficits hídricos, durante todo o período experimental.

O experimento foi instalado em delineamento de blocos casualizados, em esquema fatorial $4 \times 2 \times 2$, ou seja, foram utilizadas 4 espécies de plantas forrageiras antecessoras ao consórcio do milho com o capim-xaraés, sendo que estas foram semeadas em 2 épocas distintas (junho e julho), além de 2 épocas de adubação nitrogenada na cultura do feijão de inverno, na dose de $70 \mathrm{~kg} \mathrm{~N} \mathrm{ha}^{-1}$ (nitrato de amônio - 32\% de N). A adubação nitrogenada foi realizada com toda a dose em semeadura, sendo a aplicação na entrelinha da cultura do feijoeiro ou toda a dose em cobertura, no estádio V4, com 4 repetições.

As plantas forrageiras utilizadas nos anos agrícolas 2011/2012 e 2012/2013, com o objetivo de implantação do SPD foram a aveia preta cv. IAPAR 61 (Avena strigosa), o sorgo forrageiro cv. Volumax (Sorghum bicolor (L.) Moench), o milheto cv. ADR 500 (Pennisetum glaucum (L.) R. Br.) e o Panicum maximum cv. Tanzânia, semeadas em 02/06/2011 e 07/07/2011, no ano agrícola 2011/2012 e em 01/06/2012 e 04/07/2012 no ano agrícola 2012/2013, após a dessecação das plantas daninhas existentes na área, com o herbicida Glyphosate, na dose de 1440 g i.a ha $^{-1}$.

Todas as culturas foram semeadas mecanicamente em linha, por meio de semeadoraadubadora com mecanismo sulcador do tipo disco duplo desencontrado para SPD, com espaçamento entre linhas de 0,34 m para o sorgo, com uma densidade de 17 sementes por metro; 0,34 m para o capim-tanzânia sendo utilizados $7 \mathrm{~kg}$ de sementes ha ${ }^{-1}(\mathrm{VC}=56 \%)$; $0,34 \mathrm{~m}$ para o milheto com uma densidade de 80 sementes por metro e $0,17 \mathrm{~m}$ para a aveia preta com uma densidade de 60 sementes por metro.

Antes da semeadura do milho (híbrido simples AG 8088 YG) na safra de 2012/2013, as plantas forrageiras contidas na área experimental foram dessecadas com herbicida glifosato na dose de $1.440 \mathrm{~g}$ i.a. ha- ${ }^{-1}$, após 90 dias a partir da semeadura das mesmas. A cultura do milho foi semeada mecanicamente utilizando-se uma semeadora-adubadora com mecanismo sulcador do tipo disco duplo desencontrado para SPD, em 19/10/2012, no espaçamento de $0,90 \mathrm{~m}$. Foi realizada adubação de semeadura no milho com aplicação de $24 \mathrm{~kg} \mathrm{ha}^{-1}$ de $\mathrm{N}, 84 \mathrm{~kg} \mathrm{ha}^{-1}$ de $\mathrm{P}_{2} \mathrm{O}_{5}$ e $48 \mathrm{~kg} \mathrm{ha}^{-1}$ de $\mathrm{K}_{2} \mathrm{O}$ (300 kg ha-1 do formulado 08-28-16). A semeadura do capim-xaraés foi realizada simultaneamente à do milho, em linhas alternadas, sendo efetuada com outra semeadora-adubadora com mecanismo sulcador do tipo disco duplo desencontrado para SPD, onde foram semeadas aproximadamente duas linhas da forrageira nas entrelinhas da cultura produtora de grãos, no espaçamento de 0,34 m. A adubação nitrogenada em cobertura foi realizada a lanço no estádio V6 das plantas de milho $(13 / 11 / 2012)$ na dose de $120 \mathrm{~kg} \mathrm{ha}^{-1}$, tendo como fonte de nitrogênio a ureia.

O consórcio entre o milho e o capim-xaraés foi conduzido até 23/03/2013, data esta em que foi realizada a colheita do milho (maturidade fisiológica dos grãos). Na sequência

Cultura Agronômica, Ilha Solteira, v.26, n.3, p.285-296, 2017 
foi realizada a dessecação das plantas contidas na área com herbicida glifosato na dose de $1.440 \mathrm{~g}$ i.a. ha ${ }^{-1}$, para posterior semeadura do feijoeiro.

O feijão foi semeado mecanicamente em 13/06/2013, em SPD sob palhada de capimxaraés. Utilizou-se a cultivar Pérola, em espaçamento de $0,45 \mathrm{~m}$ entrelinhas, com densidade de 13 sementes por metro. As parcelas do experimento foram compostas por 7 linhas de feijão, com $20 \mathrm{~m}$ de comprimento, sendo a área útil as 3 linhas centrais da parcela, desprezando-se $1 \mathrm{~m}$ em cada extremidade.

A adubação de semeadura foi realizada na dose de $250 \mathrm{~kg} \mathrm{ha}^{-1}$ do formulado 04-3010, com base na análise do solo e segundo a meta de produtividade apresentada por Ambrosano et al. (1996). O N foi aplicado nas entrelinhas das plantas de feijão, em dose única na semeadura (no sulco de semeadura) ou em cobertura no estádio V4 das plantas (01/07/2013), com uso de $70 \mathrm{~kg} \mathrm{~N} \mathrm{ha}^{-1}$, tendo como fonte o nitrato de amônio $(32 \% \mathrm{~N})$. A irrigação foi realizada por aspersão com a utilização de pivô central, segundo a necessidade da cultura.

Realizou-se por ocasião do florescimento do feijoeiro (V4-R5) em 11/07/2013, leituras indiretas do índice de clorofila foliar (ICF), utilizando-se clorofilômetro digital (CFL 1030 - Falker), equipamento portátil que permite medições instantâneas na folha. As leituras foram realizadas no terceiro trifólio completamente desenvolvido, com uma média de 10 leituras por folíolo, em cinco plantas/parcela.

Nesta ocasião, foram determinados ainda os teores nutricionais em folhas de feijoeiro. Para tanto, o teor de $\mathrm{N}$ foliar foi determinado usando-se as mesmas folhas coletadas após as leituras ICF, sendo estas destacadas e acondicionadas em sacos de papel, devidamente identificadas, levadas ao laboratório e submetidas à secagem em estufa de ventilação forçada à temperatura média de $60-70^{\circ} \mathrm{C}$ até atingir massa constante. Também foram coletados uma média de 20 trifólios/parcela aleatoriamente, com o objetivo de se realizar análises dos teores de macronutientes ( $\mathrm{P}, \mathrm{K}, \mathrm{Ca}, \mathrm{Mg}$ e $\mathrm{S}$ ), efetuando-se os mesmos procedimentos descritos anteriormente para secagem das folhas. As mesmas foram moídas em moinho tipo Wiley para determinação dos teores de macronutrientes conforme metodologia descrita por Malavolta et al. (1997).

No momento da colheita do feijão (25/09/2013), foram determinados os componentes da produção e produtividade de grãos da cultura. Para tanto, foram avaliados em 10 plantas colhidas aleatoriamente por parcela (área útil), a altura de inserção da primeira vagem (AIPV), o número de vagens por planta (NVP), de grãos por planta (NGP), de grãos por vagem (NGV), e a massa de cem grãos (M100), sendo esses corrigidos para o teor de $13 \%$ umidade (base úmida). Para determinação da produtividade de grãos (PG) foram coletadas todas as plantas contidas na área útil das parcelas experimentais, sendo estas trilhadas mecanicamente e posteriormente os grãos pesados para obtenção da PG em kg ha-1, corrigidas para $13 \%$ de umidade (base úmida).

Cultura Agronômica, Ilha Solteira, v.26, n.3, p.285-296, 2017 
Os atributos avaliados foram submetidos à análise de variância pelo teste $\mathrm{F}$, e quando significativos $(\mathrm{p} \leq 0,05)$ as médias foram comparadas pelo teste de Tukey a $5 \%$ de probabilidade. As análises estatísticas foram realizadas utilizando-se o programa de computador SISVAR (FERREIRA, 2011).

\section{RESULTADOS E DISCUSSÃO}

De maneira geral, não houve interação entre os tratamentos avaliados em nenhum atributo analisado na cultura do feijoeiro durante a pesquisa. Verificou-se efeito das épocas de semeadura das plantas forrageiras (conduzidas nos anos agrícolas 2011/2012 e 2012/2013) para os teores foliares de $\mathrm{P}\left(4,7 \mathrm{~g} \mathrm{~kg}^{-1}\right), \mathrm{K}\left(26,7 \mathrm{~g} \mathrm{~kg}^{-1}\right)$ e Ca $\left(22,7 \mathrm{~g} \mathrm{~kg}^{-1}\right)$ em folhas de feijoeiro (Tabela 1), sendo que os maiores valores foram verificados na área em que as espécies forrageiras foram semeadas em julho. Em função da época da adubação nitrogenada no feijoeiro, observa-se que houve efeito para os teores de $\mathrm{K}\left(26,6 \mathrm{~g} \mathrm{~kg}^{-1}\right)$ quando o nitrogênio foi aplicado na semeadura e para o teor foliar de $\mathrm{Mg}\left(7,4 \mathrm{~g} \mathrm{~kg}^{-1}\right)$, quando aplicou-se o $\mathrm{N}$ em cobertura (Tabela 1).

Tabela 1. Teores nutricionais e índice de clorofila foliar (ICF) em folhas de feijoeiro de inverno em função de espécies forrageiras antecessoras, épocas de semeadura no inverno e adubação nitrogenada. Selvíria - Mato Grosso do Sul, 2013.

\begin{tabular}{|c|c|c|c|c|c|c|c|}
\hline & $\mathrm{N}$ & $\mathrm{P}$ & $\mathrm{K}$ & $\mathrm{Ca}$ & $\mathrm{Mg}$ & $\mathrm{S}$ & Clorofila \\
\hline Tratamentos & -------. & ---------. & ---- $(\mathrm{g} \mathrm{l}$ & $\left.g^{-1}\right)-$ & & & $\mathrm{ICF}$ \\
\hline Época de semeadura & $1,24^{\mathrm{ns}}$ & $40,15^{* *}$ & $7,63^{* *}$ & $6,22^{*}$ & $4,03^{\mathrm{ns}}$ & $2,86^{\mathrm{ns}}$ & $0,91^{\mathrm{ns}}$ \\
\hline Junho & 45,4 & $3,9 \mathrm{~b}$ & $24,9 \mathrm{~b}$ & $20,5 \mathrm{~b}$ & 7,1 & 2,1 & 36,3 \\
\hline Julho & 47,0 & $4,7 \mathrm{a}$ & $26,7 \mathrm{a}$ & $22,7 \mathrm{a}$ & 7,3 & 2,0 & 35,3 \\
\hline Espécies Forrageiras & $1,99^{\mathrm{ns}}$ & $0,77^{\mathrm{ns}}$ & $1,92^{\mathrm{ns}}$ & $1,88^{\mathrm{ns}}$ & $1,88^{\mathrm{ns}}$ & $1,90^{\mathrm{ns}}$ & $0,89^{\mathrm{ns}}$ \\
\hline Milheto & 45,4 & 4,4 & 25,5 & 20,4 & 7,0 & 2,1 & 35,2 \\
\hline Capim-tanzânia & 47,1 & 4,4 & 27,0 & 20,7 & 7,2 & 2,1 & 34,9 \\
\hline Sorgo & 48,5 & 4,2 & 25,9 & 22,5 & 7,3 & 2,2 & 36,0 \\
\hline Aveia preta & 43,8 & 4,2 & 24,8 & 22,7 & 7,2 & 2,0 & 37,0 \\
\hline Adubação Nitrogenada & $0,95^{\mathrm{ns}}$ & $2,08^{\mathrm{ns}}$ & $5,92^{*}$ & $1,15^{\mathrm{ns}}$ & $17,88^{* *}$ & $3,91^{\mathrm{ns}}$ & $1,63^{\mathrm{ns}}$ \\
\hline Semeadura & 45,5 & 4,2 & $26,6 \mathrm{a}$ & 21,1 & $6,9 \mathrm{~b}$ & 2,0 & 36,4 \\
\hline Cobertura & 46,9 & 4,4 & $25,0 \mathrm{~b}$ & 22,0 & $7,4 \mathrm{a}$ & 2,1 & 35,1 \\
\hline CV\% & 12,40 & 11,52 & 10,24 & 16,20 & 6,23 & 9,65 & 11,35 \\
\hline
\end{tabular}

Médias seguidas por letras distintas nas colunas diferem entre si pelo teste de Tukey, onde: **, *, ns: $(\mathrm{p}<0,01)$, $(\mathrm{p}<0,05)$ e $(\mathrm{p}>0,05)$, respectivamente.

Em todos os tratamentos, de maneira geral, os teores de nutrientes foliares do feijoeiro (Tabela 1) ficaram de acordo com o recomendado por Malavolta et al. (1997). Os teores de $\mathrm{P}, \mathrm{K}$ e Mg nas folhas de feijoeiro ficaram acima do indicado por Ambrosano et al. (1996) que estabeleceram as faixas de suficiência entre 2,5-4,0; 20-24; e 2,5-5,0 $\mathrm{g} \mathrm{kg}^{-1}$, para estes nutrientes, respectivamente. 
Tal fato demonstra que, a palhada das plantas forrageiras antecessoras, foram capazes de fornecer nutrientes de forma satisfatória ao feijoeiro cultivado em sucessão no sistema de rotação de culturas. Este evento pode ter ocorrido pelo aumento da disponibilidade da matéria orgânica em consequência da decomposição e mineralização dos resíduos vegetais proveniente das plantas forrageiras e da consequente disponibilização de nutrientes no solo, e também pela própria adubação de semeadura e fornecimento de nitrogênio ao feijoeiro na dose de $70 \mathrm{~kg} \mathrm{ha}^{-1}$ de $\mathrm{N}$.

Cabe ressaltar-se ainda a importância do fornecimento de $\mathrm{N}$ ao feijoeiro nestes sistemas de produção, caracterizado pela rotação de culturas com gramíneas de elevada relação $\mathrm{C} / \mathrm{N}$. Diversos trabalhos avaliando o fornecimento de $\mathrm{N}$ na cultura do feijão, nos mais variados sistemas de cultivo, demonstraram a importância da prática da adubação nitrogenada no feijoeiro (SORATTO et al., 2001; MEIRA et al., 2005; CRUSCIOL et al., 2007; MOREIRA et al., 2013; COSTA et al., 2016).

De acordo com Volpe et al. (2008), as deficiências de N são mais acentuadas em SPD do que no preparo convencional, e a rotação de culturas, com a inclusão de leguminosas ou gramíneas de baixa relação $\mathrm{C} / \mathrm{N}$, permite diminuir a intensidade das deficiências, proporcionando melhoria da produtividade e economia nos gastos com adubo nitrogenado. Em áreas de implantação do SPD (até cinco anos), com rotação de culturas, principalmente leguminosas e gramíneas forrageiras com grande potencial de produção de palhada, a imobilização de N do solo é maior que a mineralização (ANGHINONI, 2007). Nestes casos, a adubação nitrogenada é de primordial relevância a fim de suprir as necessidades nutricionais das culturas. Segundo Silveira et al. (2005), apesar da grande quantidade de N que pode estar contida na parte aérea das culturas denominadas de cobertura do solo, a quantidade real de $\mathrm{N}$ aproveitada pela cultura em sucessão dependerá do sincronismo entre a decomposição da fitomassa e a taxa de demanda da cultura sucessora.

De acordo com Leal et al. (2013), a maioria dos solos tropicais é considerado naturalmente pobre em nutrientes, como os encontrados em regiões de Cerrado. O clima favorece a rápida decomposição dos resíduos culturais, e para se obter a cobertura vegetal do solo e o suprimento inicial de "palhada" suficientes para o estabelecimento do SPD, a escolha deve recair sobre espécies de gramíneas com elevada produção de matéria seca e capacidade de proteção estável na superfície do solo (alta relação C/N) (MENEZES et al.; 2009). Dentre estas espécies destacam-se o milheto e o capim-xaraés (COSTA et al., 2014). Desta forma, o conjunto de práticas culturais adequadas, aliado ao manejo conservacionista do solo, em regiões de Cerrado, podem proporcionar maior eficiência nos sistemas produtivos atuais e proporcionar aumento na produção do feijoeiro de inverno.

Na presente pesquisa, ficou evidente a importância da presença de palhada para o bom desenvolvimento e qualidade nutricional do feijoeiro de inverno cultivado em sucessão no sistema de rotação de culturas. A importância do manejo adequado do sistema produtivo torna-se fator de extrema importância para o sucesso e rentabilidade da atividade agrícola.

Cultura Agronômica, Ilha Solteira, v.26, n.3, p.285-296, 2017 
De maneira geral, as fontes de variação avaliadas pouco influenciaram nos componentes da produção e produtividade de grãos da cultura do feijoeiro cultivado na presente pesquisa (Tabela 2), com exceção ao NGP e PG, em função de épocas de semeadura das espécies forrageiras e adubação nitrogenada na cultura do feijoeiro, respectivamente. $\mathrm{O}$ efeito das épocas de semeadura das plantas forrageiras antecessoras sobre o NGP proporcionou maiores valores quando o feijoeiro foi cultivado sobre a palhada das espécies forrageiras semeadas no mês de julho (Tabela 2). Para PG, os maiores valores foram verificados quando o fornecimento de nitrogênio foi realizado totalmente na semeadura, com valores de $3849 \mathrm{~kg} \mathrm{ha}^{-1}$.

Tabela 2. Altura de inserção da primeira vagem (AIPV), do número de vagens por planta (NVP), de grãos por planta (NGP), de grãos por vagem (NFV), da massa de 100 grãos (M100) e produtividade de grãos (PG) do feijoeiro de inverno em função de espécies forrageiras antecessoras, épocas de semeadura no inverno e adubação nitrogenada. Selvíria - Mato Grosso do Sul, 2013.

\begin{tabular}{|c|c|c|c|c|c|c|}
\hline & AIPV & NVP & NGP & NGV & \multirow{2}{*}{$\begin{array}{c}\text { M100 } \\
(\mathrm{g})\end{array}$} & \multirow{2}{*}{$\begin{array}{c}\mathbf{P G} \\
\left(\mathrm{kg} \mathrm{ha}^{-1}\right)\end{array}$} \\
\hline Tratamentos & $(\mathrm{cm})$ & \multicolumn{3}{|c|}{------ $\left(n^{o}\right.$ planta $\left.^{-1}\right)$------ } & & \\
\hline Época de Semeadura & $0,48^{\mathrm{ns}}$ & $2,68^{\mathrm{ns}}$ & $5,76^{* *}$ & $1,32^{\mathrm{ns}}$ & $0,09^{\mathrm{ns}}$ & $0,25^{\mathrm{ns}}$ \\
\hline Junho & 14,7 & 16,3 & $77,4 \mathrm{~b}$ & 4,8 & 26,7 & 3729 \\
\hline Julho & 14,1 & 17,4 & $86,3 \mathrm{a}$ & 4,9 & 26,5 & 3669 \\
\hline Espécies Forrageiras & $0,73^{\text {ns }}$ & $0,81^{\mathrm{ns}}$ & $0,68^{\mathrm{ns}}$ & $0,65^{\mathrm{ns}}$ & $1,14^{\mathrm{ns}}$ & $0,43^{\mathrm{ns}}$ \\
\hline Milheto & 15,0 & 16,1 & 79,8 & 5,0 & 26,0 & 3710 \\
\hline Capim-tanzânia & 14,3 & 17,0 & 82,8 & 4,9 & 26,8 & 3800 \\
\hline Sorgo & 14,7 & 17,5 & 85,7 & 4,9 & 26,7 & 3670 \\
\hline Aveia preta & 13,6 & 17,0 & 79,1 & 4,7 & 26,9 & 3616 \\
\hline Adubação Nitrogenada & $0,38^{\mathrm{ns}}$ & $1,34^{\mathrm{ns}}$ & $0,09^{\mathrm{ns}}$ & $0,99^{\mathrm{ns}}$ & $0,13^{\mathrm{ns}}$ & $6,33^{*}$ \\
\hline Semeadura & 14,6 & 17,3 & 82,4 & 4,8 & 26,7 & 3849 a \\
\hline Cobertura & 14,2 & 16,5 & 81,3 & 4,9 & 26,5 & $3549 \mathrm{~b}$ \\
\hline CV\% & 20,64 & 15,46 & 18,0 & 13,22 & 5,72 & 17,64 \\
\hline
\end{tabular}

Médias seguidas por letras distintas nas colunas diferem entre si pelo teste de Tukey, onde: **, *, ns: $(\mathrm{p}<0,01)$, $(\mathrm{p}<0,05)$ e $(\mathrm{p}>0,05)$, respectivamente.

$\mathrm{Na}$ presente pesquisa, as espécies forrageiras utilizadas em antecessão não influenciaram significativamente os componentes da produção e produtividade de grãos de feijão (Tabela 2). Este comportamento da cultura pode ser atribuído ao efeito das plantas antecessoras serem gramíneas (forrageiras e milho em consórcio com capim-xaraés), com maior teor de fibras (de alta relação C/N) (COSTA et al., 2014), que normalmente acarretam em maior imobilização temporária do $\mathrm{N}$ pela flora microbiana do solo, principalmente nas fases iniciais do SPD, como no presente trabalho ( $2^{\circ}$ para $3^{\circ}$ ano de implantação), portanto, resultando em maior demanda deste nutriente nas fases iniciais de desenvolvimento da cultura (ANGHINONI, 2007). 
Entretanto, os resultados obtidos na presente pesquisa são contrastantes aos obtidos por Crusciol et al. (2007) que obtiveram um aumento da produtividade do feijoeiro cultivado em sucessão a aveia-preta sob SPD e os obtidos por Silveira et al. (2005), que verificaram maior produtividade de grãos do feijoeiro de inverno sobre a palhada de milheto. De acordo com Pitol (1999), a maior produtividade sobre a palhada do milheto está relacionada com a alta capacidade de extração de nutrientes por esta espécie, disponibilizando-os consequentemente para o feijoeiro cultivado em sucessão.

Quanto às épocas de fornecimento de nitrogênio à cultura do feijoeiro de inverno (semeadura e cobertura), a maior PG obtida na adubação nitrogenada na semeadura (Tabela 2), foi semelhante aos resultados obtidos por Carvalho et al. (2001) e Moreira et al. (2013). Estes autores concluíram que doses crescentes de $\mathrm{N}$ em semeadura proporcionaram o incremento linear do rendimento de grãos do feijoeiro. Na cultura do feijão, a absorção do nitrogênio se dá praticamente durante todo o ciclo da cultura, mas a época de maior exigência ocorre quando a velocidade de absorção é máxima, isto é, entre os 35 e 50 dias após a emergência da planta (ARF et al., 1999). Deste modo, a adubação nitrogenada deve ser realizada de maneira que garanta a boa nutrição da planta, em períodos que ainda possibilitem o aumento no número de vagens por planta, período este, que se dá até o final do florescimento (ROSOLEM, 1994). Assim, por possuir ciclo curto (65-100 dias), a cultura necessita que esse nutriente esteja prontamente disponível nos momentos de maior demanda, para não limitar a produtividade da cultura (SILVA; SILVEIRA, 2000).

Solos sob cultivo continuo, principalmente no SPD, tendem, ao longo do tempo, a acumular nutrientes no perfil explorado pelas raízes, tornando menos frequente a resposta à adubação (KLUTHCOUSKI et al., 2005). Portanto, pelo histórico de três anos sob SPD da área experimental na presente pesquisa, a produtividade de grãos foi satisfatória (média de $3.700 \mathrm{~kg} \mathrm{ha}^{-1}$ ) e bem acima da média nacional (cultivo de inverno) de $1.284 \mathrm{~kg} \mathrm{ha}^{-1} \mathrm{de}$ acordo com a Conab (2015).

Em diversos trabalhos de pesquisa realizados avaliando-se a produção do feijoeiro de inverno sob SPD e adubação nitrogenada, fica evidenciado os benefícios destes sobre os componentes da produção e produtividade de grãos da cultura, assim como o verificado na presente pesquisa. Silveira et al. (2005) obtiveram produtividade do feijoeiro cv. Pérola de $1.504 \mathrm{~kg} \mathrm{ha}^{-1}$ sobre palhada de braquiária. Mingotte et al. (2014), avaliando a formação de palhada em sistemas de cultivo com a cultura do milho e Urochloa ruziziensis e consórcio entre ambos, sobre o desempenho produtivo do feijoeiro em sucessão submetido a diferentes doses de nitrogênio em cobertura, também verificaram efeito positivo da palhada advinda do sistema consorciado sobre a produtividade de grãos de feijão, obtendo produtividade média de $2.979 \mathrm{~kg} \mathrm{ha}^{-1}$. Costa et al. (2016), em trabalho realizado em condições edafoclimáticas semelhantes aos do presente estudo, também verificaram efeito positivo de palhada antecessora de capim-xaraés e adubação nitrogenada no sistema de cultivo, obtendo PG entre 3.254 a $4.309 \mathrm{~kg} \mathrm{ha}^{-1}$.

Cultura Agronômica, Ilha Solteira, v.26, n.3, p.285-296, 2017 
De acordo com Kluthcouski et al. (2005), o N que pode ser disponibilizado às plantas cultivadas em sucessão e que define em parte seu potencial produtivo, no caso da maioria das leguminosas, provém da matéria orgânica do solo, da reciclagem advinda dos resíduos de culturas anteriores e dos fertilizantes nitrogenados residuais de origem mineral ou orgânica. Assim, cabe ressaltar-se a importância da adoção de práticas conservacionistas como o SPD em sistemas produtivos tropicais, a fim de aumentar a produção agrícola e sustentabilidade destes.

Desta forma, de acordo com os resultados obtidos na presente pesquisa, recomendarse-ia como aplicação prática, o cultivo de espécies forrageiras como cobertura do solo e formação de palhada para continuidade do SPD além do fornecimento de nitrogênio todo na semeadura do feijoeiro, em condições de cultivo semelhantes às apresentadas por esta pesquisa, tendo em vista a economia com a operação de adubação em cobertura.

\section{CONCLUSÃO}

As espécies antecessoras ao cultivo do milho em consórcio com o capim-xaraés, não alteraram a nutrição, componentes da produção e produtividade de grãos do feijão de inverno em sucessão. Entretanto, quando semeadas em julho, independentemente da espécie forrageira, houve uma melhor nutrição da planta e incremento do número de grãos por planta de feijoeiro.

Em áreas de solo argiloso, com características de implantação do sistema plantio direto (primeiros 3 anos), a adubação nitrogenada fornecida totalmente em semeadura proporcionou maior produtividade de grãos de feijão de inverno em condições de Cerrado de baixa altitude.

\section{REFERÊNCIAS BIBLIOGRÁFICAS}

ANGHINONI, I. Fertilidade do solo e seu manejo em sistema plantio direto. In: NOVAIS, R. F.; V. ALVARES, V. H.; BARROS, N. F.; FONTES, R. L. F.; CANTARUTTI, R. B.; NEVES, J. C. L. (Ed.). Fertilidade do solo. Viçosa: SBCS, 2007. cap. 15, p. 873-928.

AMBROSANO, E. J.; TANAKA, R. T.; MASCARENHAS, H. A. A.; RAIJ, B. VAN; QUAGGIO, J. A.; CANTARELA, H. Leguminosas e oleaginosas. In: RAIJ, B. van; CANTARELA, H.; QUAGGIO, J. A.; FURLANI, A. M. C. Recomendações de adubação e calagem para o Estado de São Paulo. 2.ed. Campinas: Instituto Agronômico e Fundação IAC, 1996. cap. 19, p. 189-203.

ARF, O.; FERREIRA, E. C.; CARVALHO, M. A. C.; SÁ, M. E.; BUZETTI, S. Efeito de doses e parcelamento da adubação nitrogenada em cobertura na cultura do feijão. In: REUNIÃO NACIONAL DE PESQUISA DE FEIJÃO, 6., 1999, Salvador. Resumos Expandidos. Goiânia: Embrapa, 1999. p. 790-793.

Cultura Agronômica, Ilha Solteira, v.26, n.3, p.285-296, 2017 
CARVAlHO, M. A. C.; ARF, O.; SÁ, M. E.; BUZETTI, S.; SANTOS, N. C. B.; BASSAN, D. A. Z. Produtividade e qualidade de sementes de feijoeiro (Phaseolus vulgaris L.) sob influência de parcelamentos e fontes de nitrogênio. Revista Brasileira de Ciência do Solo, Viçosa, v. 25, n. 3, p.617-624, 2001.

COMPANHIA NACIONAL DE ABASTECIMENTO - CONAB. Acompanhamento da safra brasileira de grãos, Safra 2014/15, Quarto Levantamento, v. 2, n. 4, 2015. Disponível em: http://www.conab.gov.br. Acesso em: 14 jun. 2015.

COSTA, N. R.; ANDREOTTI, M.; BUZETTI, S.; LOPES, K. S. M.; SANTOS, F. G.; PARIZ, C. M. Acúmulo de macronutrientes e decomposição da palhada de braquiárias em razão da adubação nitrogenada durante e após o consórcio com a cultura do milho. Revista Brasileira de Ciência do Solo, Viçosa, v. 38, n. 4, p.1223-1233, 2014.

COSTA, N. R.; ANDREOTTI, M.; LOPES, K. S. M.; YOKOBATAKE, K. L. A.; LIMA, C. G. R. Winter bean productivity under Urochloa straw fertilized with nitrogen. Revista Caatinga, Mossoró, v. 29, n. 1, p.133-142, 2016.

CRUSCIOL, C. A. C.; SORATTO, R. S.; SILVA, L. M. D.; LEMOS, L. B. Fontes e doses de nitrogênio para o feijoeiro em sucessão a gramíneas no sistema plantio direto. Revista Brasileira de Ciência do Solo, Viçosa, v. 31, n. 6, p.1545-1552, 2007.

EMPRESA BRASILEIRA DE PESQUISA AGROPECUÁRIA - EMBRAPA. Sistema brasileiro de classificação de solos. 2. ed. Rio de Janeiro: CNPS, 2006. 306 p.

FAGERIA, N. K.; BALIGAR, V. C. Enhancing nitrogen use efficiency in crop plants. Advances in Agronomy, Maryland Heights, v. 88, n. 4, p.97-185, 2005.

FERREIRA, D. F. Sisvar: Sistema de análise de variância. Ciência e Agrotecnologia, Lavras, v. 35, n. 6, p.1039-1042, 2011.

KLUTHCOUSKI, J.; AIDAR, H.; THUNG, M.; OLIVEIRA, F. R. A. Manejo antecipado do nitrogênio nas principais culturas anuais. Santo Antônio de Goiás: Embrapa Arroz e Feijão, 2005. 63 p. (Embrapa Arroz e Feijão. Documentos, 187).

LEAL, A. J. F.; LAZARINI, E.; RODRIGUES, L. R.; MARCANDALLI, L. H. Adubação nitrogenada para milho com o uso de plantas de cobertura e modos de aplicação de calcário. Revista Brasileira de Ciência do Solo, Viçosa, v. 37, n. 2, p.491-501, 2013.

MALAVOLTA, E.; VITTI, G. C.; OLIVEIRA, S. A. Avaliação do estado nutricional das plantas: princípios e aplicações. 2. ed. Piracicaba: Associação Brasileira para Pesquisa da Potassa e do Fosfato, 1997. 319 p.

MEIRA, F. A.; SÁ, M. E.; BUZETTI, S.; ARF, O. Doses e épocas de aplicação de nitrogênio no feijoeiro irrigado cultivado em plantio direto. Pesquisa Agropecuária Brasileira, Brasília, v. 40, n. 4, p.383-388, 2005.

MENEZES, L. A. S.; LEANDRO, W. M.; OLIVEIRA JUNIOR, J. P.; FERREIRA, A. C. B.; SANTANA, J. G.; BARROS, R. G. Produção de fitomassa de diferentes espécies, 
isoladas e consorciadas, com potencial de utilização para cobertura do solo. Bioscience Journal, Uberlândia, v. 25, n. 1, p.7-12, 2009.

MINGOTTE, F. L. C.; YADA, M. M.; JARDIM, C. A.; FIORENTIN, C. F.; LEMOS, L. B.; FORNASIERI FILHO, D. Sistemas de cultivo antecessores e doses de nitrogênio em cobertura no feijoeiro em plantio direto. Bioscience Journal, Uberlândia, v. 30, n. 5, p.696706, 2014.

MOREIRA, G. B. L.; PEGORARO, R. F.; VIEIRA, N. M. B.; BORGES, I.; KONDO, M. K. Desempenho agronômico do feijoeiro com doses de nitrogênio em semeadura e cobertura. Revista Brasileira de Engenharia Agrícola e Ambiental, Campina Grande, v. 17, n. 8, p.818-823, 2013.

PITOL, C. O milheto em sistemas de plantio direto. In: WORKSHOP INTERNACIONAL DE MILHETO, 1., 1999, Planaltina. Anais... Planaltina: Embrapa Cerrados, 1999. p. 69-71.

ROSOLEM, C. A.; MARUBAYASHI, O. M. Seja o doutor do seu feijoeiro. Informações Agronômicas, Piracicaba, v. 68, n. 68, p.1-16, 1994.

SILVA, C. C.; SILVEIRA, P. M. Influência de sistemas agrícolas na resposta do feijoeiro (Phaseolus vulgaris L.) irrigado à adubação nitrogenada em cobertura. Pesquisa Agropecuária Tropical, Goiânia, v. 30, n. 1, p.86-96, 2000.

SILVEIRA, P. M.; BRAZ, A. J. B. P.; KLIEMANN, H. J.; ZIMMERMANN, F. J. P. Adubação nitrogenada no feijoeiro cultivado sob plantio direto em sucessão de culturas. Pesquisa Agropecuária Brasileira, Brasília, v. 40, n. 4, p.377-381, 2005.

SORATTO, R. P.; SILVA, T. R. B.; ARF, O.; CARVALHO, M. A. C. Níveis e épocas de aplicação de nitrogênio em cobertura no feijoeiro irrigado em plantio direto. Cultura Agronômica, Ilha Solteria, v. 10, n. 1, p.89-99, 2001.

VOLPE, E.; MARCHETTI, M. E.; MACEDO, M. C. M.; ROSA JÚNIOR, E. J. Renovação de pastagem degradada com calagem, adubação e leguminosa consorciada em Neossolo Quartzarênico. Acta Scientiarum Agronomy, Maringá, v. 30, n. 1, p.131-138, 2008. 